\title{
Triple Quadrupole Mass Spectrometry as Applied to Flame Diagnostics: Study of the $\mathrm{C}_{2} \mathrm{H}_{4} / \mathrm{N}_{2} \mathrm{O} /$ Ar Flame
}

\author{
Stephen L. Howard*, Joyce E. Newberry, Rosario C. Sausa, \\ and Andrzej W. Miziolek \\ U.S. Army Research Laboratory, Aberdeen Proving Ground, Maryland, USA
}

A recently developed research apparatus for characterization of low-pressure premixed flames has been developed and was used to characterize the $\mathrm{C}_{2} \mathrm{H}_{4} / \mathrm{N}_{2} \mathrm{O} /$ Ar flame at 20 torr. This instrument incorporates several diagnostic techniques in one apparatus so that individual techniques can be quantitatively compared and the usable detection range (both in terms of resolution and species detection) expanded. Results discussed in this report include mass analysis by triple quadrupole mass spectrometer and temperature measurement by thermocouple. Concentration profiles in the one-dimensional flame include $\mathrm{CO}, \mathrm{N}_{2}$, and $\mathrm{C}_{2} \mathrm{H}_{4}$ at nominal $m / z 28$ as well as $\mathrm{CO}_{2}$ and $\mathrm{N}_{2} \mathrm{O}$ at $\mathrm{m} / \mathrm{z}$ 44. (J Am Soc Mass Spectrom 1993, 4, 152-158)

$\Lambda$ good deal is yet unknown about the actual reaction mechanisms in many of the flames that comprise a large share of the power and propulsion generation systems in use today. It is becoming increasingly important to energy considerations and environmental concerns that such mechanisms are known. Flame optimization with particular attention to product formation and thermal efficiency requires this information.

Various laser spectroscopic techniques have been developed that work in the flame environment. Laserinduced fluorescence and multiphoton techniques such as resonance-enhanced multiphoton ionization have yielded measurements with a good degree of selectivity and spatial resolution [1-3]. More intrusive techniques for gas sampling that use gas liquid chromatography $(\mathrm{GC})$ or mass spectrometry as detectors have also been used [4-9]. As with the laser-based techniques, these techniques have advantages for some flame species and flame conditions and disadvantages for others. While study of ions produced in a flame is a long-invesligated problem [10] and mass spectrometry of flame neutrals had early beginnings [11], the bulk of the subsequent research is more recent $[5,6,12-14]$.

Gas sampling by quartz microprobe $[7-9,15]$ has been shown to be adequate for stable species and therefore well suited for GC studies. However, resi-

\footnotetext{
* Former NAS/NRC Postdoctoral Research Associate, presently a staff member at the Army Research Laboratory, Propulsion Branch

Address reprint requests to Stephen L. Howard, U.S. Army Physics Research Laboratory, AMSRL-WT-PE, Aberdeen Proving Ground, MD 21005.
}

dence times within the probe at significant pressures preclude this technique for reactive species. Most mass spectrometry studies of radical intermediates have been done by molecular beam sampling techniques; indeed, the supersonic jet that forms the molecular beam is essential in preserving the radicals until they can be ionized. Comparison of $\mathrm{OH}$ radical concentration profiles determined by optical methods with those determined by molecular beam mass spectrometry (MB/MS) has shown that minor perturbations occur only in the preheat zone but the flame zone and postflame regions are essentially undisturbed $[5,12$, 16]. In order to more fully characterize the possible operating range of each technique and to quantitatively compare results between techniques, a hybrid instrument for analysis of flames under the same operating conditions was developed. Previous work [16] with $\mathrm{C}_{2} \mathrm{H}_{4} / \mathrm{O}_{2} /$ Ar flames at 20 torr with the present instrument showed that laser-based diagnostics for this simple flame were most appropriate for analysis close to the burner surface $(0-2 \mathrm{~mm})$. Molecular beam mass spectrometry was able to investigate many more species concurrently and could also provide greater detail for some species higher in the reaction zone. Both methods appeared to be equivalent, for all cases where comparison could be made, in the burnt gas region far removed from the burner surface. It was concluded that in the current instrument MB/MS, while not immune to perturbation by the quartz sampler, adequately describes nascent chemistry in the flame environment. Studies were therefore extended to a relatively more complex flame, the current study 
$\left(\mathrm{C}_{2} \mathrm{H}_{4} / \mathrm{N}_{2} \mathrm{O} / \mathrm{Ar}\right)$, so that the differentiation power of the triple quadrupole could be evaluated prior to attempting to study complex flames such as are found in real environments.

\section{Experimental}

\section{Sampling System}

All of the flames in this study were operated at 20 torr absolute pressure. The instrument has been described earlier [16] and only its salient components are mentioned here. The low-pressure burner chamber was a stainless steel cylinder with an inside nominal diameter of $25 \mathrm{~cm}$ and a height of $40 \mathrm{~cm}$. Temperature measurement by thermocouple ( $125 \mu \mathrm{m}$ diameter platinum/platinum-10\% rhodium wire coated with a noncatalytic beryllium/yttrium oxide mixture [17]) was provided.

The mass spectrometer consisted of an Extrel (Pittsburgh, PA) C50 TQMS in-line triple quadrupole mass filter with a concentric-axis ionizer. Sampling of the flame gases occurred through a conical quartz skimmer with a $250-\mu \mathrm{m}$ diameter orifice. The gases expanded supersonically into the first differential vacuum chamber with a measured average chamber pressure of $5 \times 10^{-5}$ torr. The expanding gases were then formed into a supersonic beam by collimation through a second skimmer (Beam Dynamics, Minneapolis, MN, Model 2, orifice diameter $2 \mathrm{~mm}$ ) and introduced into the ionization region of the first quadrupole (the first set of quadrupoles, Q1, was used for mass analysis except where noted), which was maintained at $1 \times$ $10^{-6}$ torr. The beam was then modulated at $200 \mathrm{~Hz}$ with a tuning fork chopper and ionized prior to entering the first quadrupole. The electron emission current was maintained at $0.10 \pm 0.01 \mathrm{~mA}$ and the nominal energy at $17.0 \pm 0.1 \mathrm{eV}(0.5 \mathrm{eV}$ FWHM $)$ unless otherwise noted. The drawout voltage from the ionizer was set at less than $1 \mathrm{~V}$. These ionizing conditions optimized and stabilized the modulated beam. At higher emission currents heat radiated from the ionizer filament would heat the tuning fork and cause it to lose resonance. When the chopper lost resonance, the phase lock was lost and the chopper blocked the beam. Higher drawout voltages also affected the beam. The higher voltages tend to collect more of the background gas ions (as it was originally designed as a residual gas analyzer) and reduce the signal-to-noise ratio by increasing the noise.

A beam stop was included to determine if the modulated beam was a molecular beam (modulation would cease with beam stop activated) or an effusive beam (no change in modulation noted with beam stop activated). After traversing the quadrupoles the ion current was detected with a continuous-dynode electron multiplier. Amplified current from the detector then was processed with a Stanford Research System (Sunnyvalle, CA) model SR530 lock-in amplifier to discriminate signal from background gases and to signal average in order to increase sensitivity.

The tlame was produced upon and supported by a McKenna (Pittsburg, CA) flat burner. Under proper gas flow conditions the flame was produced in a laminar flow field with the flame front parallel to the burner surface and therefore one-dimensional with respect to the burner surface. Subsequently, the distance from the burner surface to a sampling point in the flame can be used as the reaction coordinate to describe the progress of reaction in terms of species concentration profiles as well as temperature profiles. In order to increase the spatial resolution the flame was operated at reduced pressure and argon gas was added as dilutent. Low-pressure (or subatmosphere) flames have shown that the reaction zones expand with minimal distortion as pressure is reduced $[18,19]$.

The reactant gases were of commercial high-purity grade and were metered by MKS (Andover, MA) mass flow controllers and premixed in the McKenna burner prior to passing through the flat $6-\mathrm{cm}$ diameter sintered stainless steel plug in the center of the burner surface. Gas flows of $\mathrm{C}_{2} \mathrm{H}_{4 r} \mathrm{~N}_{2} \mathrm{O}$, and $\mathrm{Ar}$ of $0.53,3.2$, and 1.0 liter (STP)/min, respectively, were used that resulted in linear flow rates on the order of $106 \mathrm{~cm} / \mathrm{sec}$ (Reynolds number on the order of 150, indicating operation well within the laminar regime). The sintered stainless steel frit was water cooled to maintain a constant temperature as measured by imbedded alumel-chromel thermocouples. This central frit was encircled by another sintered metal frit through which argon was flowed, thus forming a protective shroud that minimized mixing of any recirculating burnt gases in the low-pressure chamber. The burner was mounted normal to the center of the burner chamber on a high-vacuum feedthrough flange that was coupled to a $\theta z$ translation stage. This stage allowed independent horizontal scanning (precision in $\theta$ of less than one degree) of the burner and vertical motion (precision on the order of $50 \mu \mathrm{m}$ ) allowed the diagnostics to remain stationary while "scanning" the flame (scanning the distance between the diagnostics and the burner surface).

\section{Calibration Procedure}

Several problems exist with using a moderately low resolution mass spectrometer with electron-impact ionization as the detector of flame species. The ionization technique is not "soft" (i.e., fragmentation patterns occur for virtually every polyatomic species) and final ion currents depend hedvily on ionization potentials and cross sections. For stable species this problem was addressed by preparing calibration gas mixtures that were introduced into the burner chamber at flame conditions. The nominal energy of the electron beam during calibration was maintained at $17.0 \mathrm{eV}$ (this value was chosen because it is below the ionization energy at which $\mathrm{OH}$ is produced from $\mathrm{H}_{2} \mathrm{O}$, yet above 
that required to ionize Ar). At this energy fragmentation of the primary ion beam was small.

All of the calibration mixtures contained argon (used in all the flames to dilute the flame and to increase spatial resolution). Since it is not produced or consumed in the flame and its ionization cross section changes minimally at flame temperatures, it was considered as an ideal internal standard. The observed mass spectrum signal can be described as

$$
I_{i}=S_{i} X_{i}
$$

where $I_{i}$ is the observed ion current, $S_{i}$ is a sensitivity factor (with appropriate units) containing instrument and ionization dependent information, and $X_{i}$ the mole fraction, partial pressure, or other relevant concentration unit for the $i$ th component. Thus the ratio of $S_{i}$ to the sensitivity factor of an internal standard (such as argon),

$$
K_{i}=S_{i} / S_{\mathrm{Ar}}
$$

may be used in the following manner to quantify the amount of the $i$ th component present:

$$
X_{i}=X_{\mathrm{Ar}}\left(\frac{I_{i}}{I_{\mathrm{Ar}}}\right) \frac{1}{K_{i}}
$$

The validity of eqs 2 and 3 was verified in the flame by first measuring $S_{\mathrm{He}} / S_{\mathrm{Ar}}$ at ambient temperature and 20 torr pressure with a known mixture of helium and argon. This ratio was then measured under flame conditions by introducing a known concentration of $\mathrm{He}$ in the argon flow. Measurements were taken at various points from the burner surface through the flame front and into the burnt gas region. The assumption of one dimensionality was also tested by horizontally scanning across the flame at each point. The radially measured ratios were the same within experimental error in all cases, thereby verifying the above assumptions.

Another problem arose with use of only moderate mass resolution. Several molecules may exhibit the same nominal mass-to-charge ratio. $\mathrm{CO}_{2}$ and $\mathrm{N}_{2} \mathrm{O}$ (nominal $m / z 44$ ) were a case in point. Differentiation of such species pairs was possible with the triple quadrupole mass spectrometer through the use of collision-induced dissociation (CID) of the ions in the primary ion beam to produce fragmentation patterns unique to each molecule studied. The first quadrupole, $\mathrm{Q1}$, selected ions of interest in the ionized beam. These ions then passed through the rf-only quadrupole, Q2, where collision with argon maintained at a pressure of $10^{-3}$ torr occurred at a laboratory energy of approximately $50 \mathrm{eV}$. Upon collision the selected ions fragmented and the daughter fragments were analyzed in the third quadrupole, Q3. Table 1 delineates the CID reactions used in this study to distinguish overlapped major species. As noted in Table 1 for $\mathrm{CO}_{2}$, even
Table 1. CID reactions used to differentiate major species*

$$
\begin{aligned}
\mathrm{CO}^{+} & \rightarrow \mathrm{C}^{+}+\mathrm{O} \\
\mathrm{C}_{2} \mathrm{H}_{4}^{+} & \rightarrow \mathrm{C}_{2} \mathrm{H}_{3}^{+}+\mathrm{H} \\
\mathrm{N}_{2}^{+} & \rightarrow \mathrm{N}^{+}+\mathrm{N} \\
\mathrm{CO}_{2}^{+} & \rightarrow \mathrm{O}+\mathrm{CO}^{+} \rightarrow \mathrm{C}^{+}+2 \mathrm{O} \\
\mathrm{N}_{2} \mathrm{O}^{+} & \rightarrow \mathrm{NO}^{+}+\mathrm{N}
\end{aligned}
$$

${ }^{\star} \mathrm{CO}_{2}^{+}$and $\mathrm{N}_{2} \mathrm{O}^{+}$both produced $m / z 28$ as the major $\mathrm{CID}$ peak Miriur utaks at $m / z 12$ and 30 , respectlvely, were therefore used.

simple, single-collision CID does not always give the information necessary to differentiate between two species. Since multivariate analysis was not used in this study, the collision gas pressure was maintained high enough that multiple collisions were possible.

Calibration gas mixtures of each gas with argon and also with each species possible at a given mass-tocharge ratio of interest were prepared and the fragmentation patterns and branching ratios obtained. A word of clarification - the intensity of each primary or fragment peak obtained during calibration is compared to that of argon, which is measured concurrently and sensitivity factors obtained through use of eq 2 (sensitivity factors are instrument dependent so the values used for this particular instrument are not listed in this study). During a flame measurement, the intensity of the same peak is compared to the argon peak and the mole fraction of the species is obtained via eq 3.

Such calibration procedures were performed only for stable gases. Radicals and reactive intermediates require other techniques (where possible) for quantification. Therefore only relative profiles were obtained in this study for these species. However, at a particular mass-to-charge ratio, when more than one species was possible, CID was used to determine the respective contributions. With the current data acquisition system (e.g., a strip chart recorder for final data output) constituents of the same overlapped peak are observable only at levels exceeding one percent of the major constituent. Improvements in data acquisition and/or multivariate postanalysis of the data with the calibration factors obtained as described in the previous paragraph should improve the relative sensitivity of the CID measurements.

\section{Results and Discussion}

In this article temperature and mass spectrometric measurements are reported of many of the reactive and stable flame species in a stoichiometric, premixed $\mathrm{C}_{2} \mathrm{H}_{4} / \mathrm{N}_{2} \mathrm{O} / \mathrm{Ar}$ flame at 20 torr. The temperature profile of the flame (Figure 1) was obtained with a 125- $\mu \mathrm{m}$ diameter $\mathrm{Pt} / \mathrm{Pt}(10 \% \mathrm{Rh})$ thermocouple. The thermocouple wire in the flame was coated with a noncatalytic coating as described in the experimental section in order to avoid catalytic heating on the thermocouple that would otherwise lead to erroneous temperatures and/or break the thermocouple due to localized heat- 


$$
\begin{gathered}
\mathrm{C}_{2} \mathrm{H}_{4} / \mathrm{N}_{2} \mathrm{O} / \mathrm{Ar} \text { Flame at } 20 \text { Torr } \\
\mathbf{\Phi}-1.0
\end{gathered}
$$

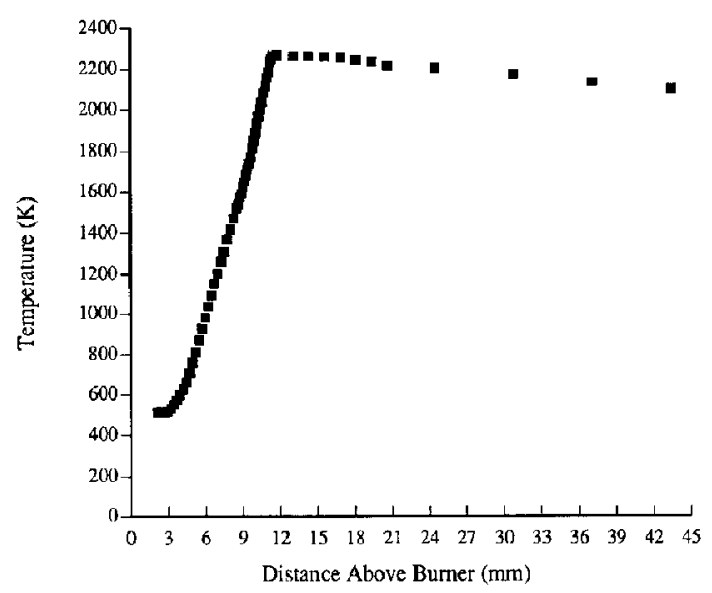

Figure 1. Temperature profile of $\mathrm{C}_{2} \mathrm{H}_{4} / \mathrm{N}_{2} \mathrm{O} /$ Ar flame, $\Phi=1$ ( $\Phi$ defined as the ratio of initial moles of fuel to oxidizer divided by the ratio of the respective stoichiometric coefficients) at 20 torr.

ing. After coating, the temperatures obtained were corrected for radiative heat losses.

This correction was approximated by equating the heat transferred to the thermocouple from the gases to that lost by radiation. The corrective term is given by $[20,21]$

$$
\Delta T=T_{\text {cal }}-T_{\text {obs }}=\epsilon \sigma d\left(T_{\text {obs }}^{4}-T_{0}^{4}\right) / 2 k
$$

where $\epsilon$ is the emissivity of the coated thermocouple (taken to be 0.6) [21], $\sigma$ is the Stefan-Boltzmann constant, $d$ is the diameter of the junction, $k$ is the thermal conductivity of the gases present at the sampling region (usually approximated with values for air), and $T_{0}$ is approximately $300 \mathrm{~K}$. The actual thermal conductivity at each point in the flame was obtained as a function of temperature using empirical expressions [22] and corrected for gas composition as measured in this study. The value for $k$ of the gas mixture varied from $8.41 \times 10^{-5}$ to $4.09 \times 10^{-4} \mathrm{cal} \mathrm{sec}^{-1} \mathrm{~cm}^{-1} \mathrm{~K}^{-1}$. The diameter of the coated thermocouples was measured as $190 \mu \mathrm{m}$. The uncertainty in temperature measurements was estimated to be $50 \mathrm{~K}$ in the region of peak temperature and $10 \mathrm{~K}$ in the preheat region.

The temperature profile in Figure 1 clearly demonstrates flame gas temperatures near the burner surface (about $510 \mathrm{~K}$ ) that are in excess of that measured by the imbedded thermocouples (about $310 \mathrm{~K}$ ). Typically, models require the temperature at the burner interface in order to establish boundary conditions at the burner. The temperature profile should be smooth without discontinuities such as that apparently displayed at the burner. Unless thermocouple or other exacting temperature measurements are made very close to the burner surface (or in the upper few atomic layers of the burner itself) the bulk temperature of the burner or an assumed temperature is used to establish the boundary conditions. Unless the temperature difference between the burner and the gas immediately above it is known, error would otherwise be introduced in the calculations. At this time the models require a set temperature at the boundary for implementation of the code and cannot calculate such a temperature from the energy equations.

The region between 0 and approximately $6 \mathrm{~mm}$ above the surface is typical of the "dark" or preheat zone of the flame. From 6 to $12 \mathrm{~mm}$ the major flame chemistry occurs. This region of steep temperature gradient also contains the visible luminous zone (a light purple or violet color). Above $15 \mathrm{~mm}$ is the burnt gas region. This region is on average the hottest region of the flame and is in partial equilibrium (major flame intermediates such as $\mathrm{H}, \mathrm{O}$ and $\mathrm{OH}$ are still in abundance [16]). As the distance above the burner is greatly increased beyond that indicated in Figures 1-6, the flame cools because of radiative and convective heat losses to the combustion chamber. As the flame cools, radical concentrations diminish and eventually disappear, leaving only stable products. Profile measurements were not continued into this region for several reasons. Foremost, one-dimensionality of the flame at extended distances above the burner surface is not expected, because the combustion chamber diameter is bigger than that of the burner, and while plug flow does occur from the burner into the chamber, the flow streamlines eventually expand to fill the full diameter of the chamber. This expansion induces turbulence and one-dimensionality of the flow is lost. Another incidental reason concerns current modeling efforts. As mentioned previously, temperature effects near boundary layers are currently not modeled well. In general, the

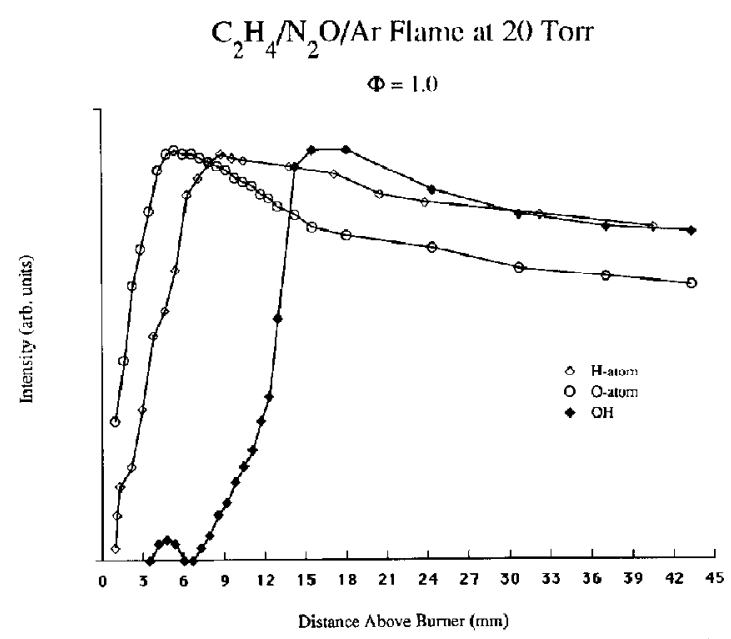

Figure 2. Profiles of $\mathrm{H}$-atom $(\diamond), \mathrm{O}$-atom $(\mathrm{O})$, and $\mathrm{OH}(\bullet)$ intermediates of stoichiometric $\mathrm{C}_{2} \mathrm{H}_{4} / \mathrm{N}_{2} \mathrm{O} / \mathrm{Ar}$ flame at 20 torr. Individual profiles normalized to unity. 


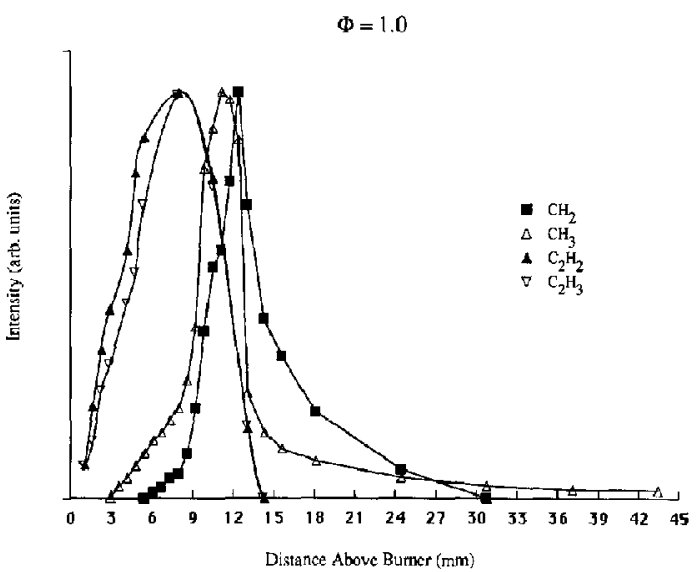

Figure 3. Profiles of major hydrocarbon intermediates of stoichiometric $\mathrm{C}_{2} \mathrm{H}_{4} / \mathrm{N}_{2} \mathrm{O} / \mathrm{Ar}$ flame at 20 torr. Individual profiles normalized to unity.

importance of each heat loss mechanism (radiative, conductive, and convective) at each stage of the flame is fiercely debated among modelers. It is still questioned as to whether a measured temperature profile will correct adequately for such heat losses. Therefore measurements of temperature and chemical species were not obtained in this uncertain region $(d>50$ $\mathrm{mm}$ ).

Further evidence of the major reactivity zone from 6 to $12 \mathrm{~mm}$ is the concentration profiles of major radical species. Figures 2 and 3 exhibit several such profiles. Figure 2 shows profiles for $\mathrm{H}, \mathrm{O}$, and $\mathrm{OH}$. These species form a cadre of important flame radicals that are present in virtually all flames and have been studied in many different flames. They are formed early in the combustion and persist well into the burnt gas

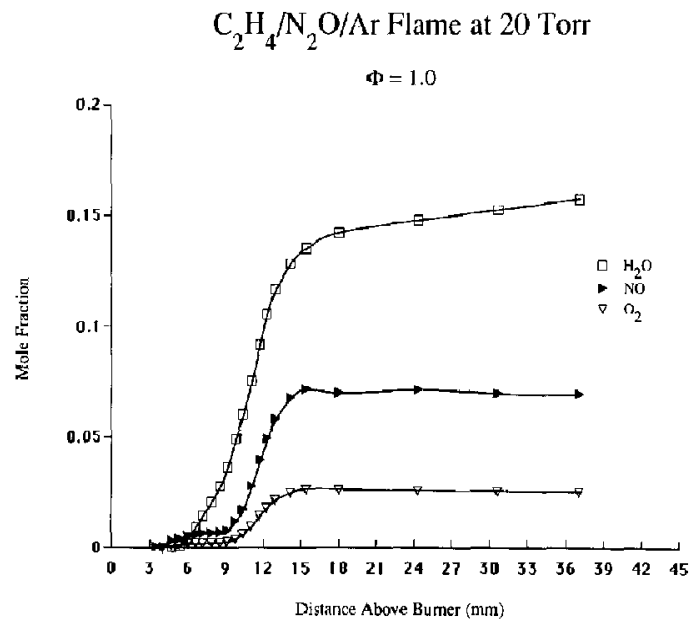

Figure 4. Profiles of $\mathrm{H}_{2} \mathrm{O}, \mathrm{NO}$, and $\mathrm{O}_{2}$ in stoichiometric $\mathrm{C}_{2} \mathrm{H}_{4} / \mathrm{N}_{2} \mathrm{O} / \mathrm{Ar}$ flame at 20 torr. Concentrations listed as mole fraction.

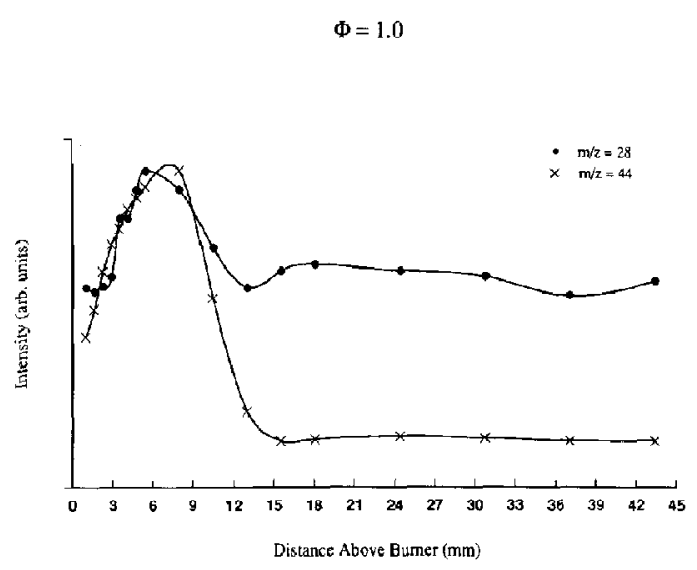

Figure 5. Total observed ion signals at $m / z 28$ and 44 for stoichiometric $\mathrm{C}_{2} \mathrm{H}_{4} / \mathrm{N}_{2} \mathrm{O} / \mathrm{Ar}$ flame at 20 torr.

region. The peak near $5 \mathrm{~mm}$ in the $\mathrm{OH}$ profile has been noted for other flames [16] and is found in approximately the lower half of the luminous zone of the flame. This feature has been attributed in other flames to competition between the high-temperature formation of $\mathrm{OH}$ via chain-branching and by three-body reactions which are favored at lower temperature $[16,23]$.

Radicals produced solely by fuel gases appear near the prehcat zone, rcach maximum, and disappear within the luminous zone. In Figure 3, the intermediates most closely related to the primary fuel occur first. Their concentrations increase rapidly in the preheat zone, begin to diminish as the primary fuel is exhausted, and disappear near the top of the luminous zone. As concentrations of $\mathrm{C}_{2} \mathrm{H}_{2}$ and $\mathrm{C}_{2} \mathrm{H}_{3}$ increase,

$$
\begin{gathered}
\mathrm{C}_{2} \mathrm{H}_{4} / \mathrm{N}_{2} \mathrm{O} / \mathrm{Ar} \text { Flame at } 20 \text { Torr } \\
\qquad \boldsymbol{\Phi}=1.0
\end{gathered}
$$

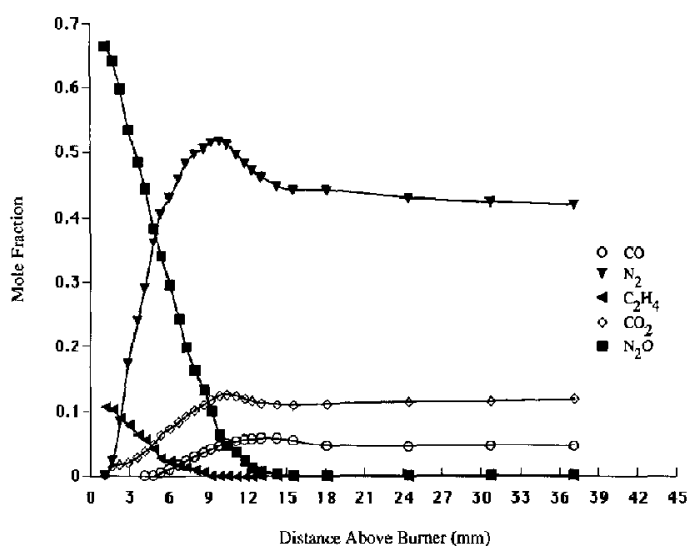

Figure 6. Concentration profiles (mole fraction) of species found by $\mathrm{CID}$ at $m / z 28$ and 44 in stoichiometric $\mathrm{C}_{2} \mathrm{H}_{4} / \mathrm{N}_{2} \mathrm{O} / \mathrm{Ar}$ flame at 20 torr. Compare to total ion signals prior to $\mathrm{CID}$ in Figure 7 . 
one of their fragments, $\mathrm{CH}_{3}$, is formed. This profile is in turn closely followed by $\mathrm{CH}_{2}$. These two radicals exist primarily in or just above the luminous zone.

Profiles of stable species for which mass assignment is not ambiguous are reported in Figure 4. These species are all flame products. $\mathrm{NO}$ and $\mathrm{O}_{2}$ appear to be produced by predominately high-temperature reactions in the upper regions of the luminous zone. Essentially none of these two products appears below 2000 $\mathrm{K}$ (see Figure 1), and both reach maximum concentration near $2300 \mathrm{~K}$. Since $\mathrm{O}_{2}$ appears just after $\mathrm{NO}$ and has the same profile shape, it is likely that it is produced by the following high-temperature reaction [24]:

$$
\mathrm{NO}+\mathrm{O} \rightarrow \mathrm{N}+\mathrm{O}_{2}
$$

Figure 5 shows total ion currents observed at nominal $m / z 28$ and 44 (each profile normalized to unity). These profiles show the sum of the concentrations of all species at these masses. Each profile was obtained using a single quadrupole for mass identification with an approximate resolution of $700(\mathrm{~m} / \Delta \mathrm{m})$. As shown, little information is available prior to utilizing CID to differentiate between species. This result is not, however, outside of reasonable expectations. Sufficient resolution to distinguish the expected species at $m / z 28$ and 44 is much greater than that generally obtainable with a quadrupole mass analyzer.

However, it is informative to note that both profiles increase during the preheat region (with some initial lag of $m / z 28$ ), maximize in the luminous zone, diminish, and rapidly achieve a steady state in the burnt gas region. It should be noted that each profile is the sum of at least two species of differing sensitivity facturs (differences of up to a factor of 12 are possible) and corresponding concentrations. The experiment was therefore repeated at $m / z 28$ and 44 , this time utilizing the entire triple quadrupole mass filter with collision gas present in the second quadrupole. The mole fraction of each gas was then obtained from eq 3 using sensitivity factors obtained during calibration as explained in the experimental section.

Comparison of Figures 5 and 6 demonstrates the utility of using CID to obtain the identity of flame species at the same nominal mass. In Figure 6, the species lumped into nominal $m / z 28$ and 44 in Figure 5 are clearly discerned and the progress of the reaction is now easily traced by looking at the consumption of reactants and the evolution of major products. (For profile of other products see Figure 3 .)

The reasons for some of the structure found in the combined profiles in Figure 5 are now also apparent. The delay of $m / z 28$ relative to $m / z 44$ is due to utilization of $\mathrm{C}_{2} \mathrm{H}_{4}$ with formation of only small amounts of $\mathrm{N}_{2}$ early in the preheat zone. The abundance of $\mathrm{N}_{2}$ then quickly increases with only relatively small expenditure of $\mathrm{C}_{2} \mathrm{H}_{4}$ for several millimeters. The maximum in both profiles is postulated as the result of diffusion of product gases from the burnt gas region into the luminous zone, thus increasing signal over that expected. Since plug flow does exist in the flame, back diffusion decreases as distance from the burnt gas region is increased. While most quantitative evidence of back diffusion is obtained by model calculations, the maximum and rate of decrease in the profiles in Figure 5 in the region of 6 to $16 \mathrm{~mm}$ indicate that back diffusion does occur. Because back diffusion rates are mass dependent, it is expected that $m / z 28$ should diffuse more rapidly and penetrate more deeply into the luminous zone than $m / z 44$. Comparison of the profiles shows that such is the case with $m / z 28$ peaking near $6 \mathrm{~mm}$ and the postluminous zone minimum near $14 \mathrm{~mm}$. The corresponding points for $\mathrm{m} / \mathrm{z}$ 44 occur near 9 and $15 \mathrm{~mm}$, respectively.

Further evidence of back diffusion is evidenced in Figure 6. While the sum of the mole fractions of all species at each point in the flame is unity (argon mole fraction not plotted), it is only early in the preheat zone and late in the burnt gas region where the number of moles of each constituent atom $(\mathrm{C}, \mathrm{N}, \mathrm{O}$, and $\mathrm{H}$ ) is equal to that present in the premixed reactant gases. During the luminous zone and early in the burnt gas region the number of moles of each atom increases and decreases in the same manner as that shown in Figure 5. Without diffusion the number of moles of constituent atoms would be constant across the flame. One line of reasoning that would otherwise invalidate this argument is the fact that not all theoretically possible species are reported in this study. If some species are not reported, then flame chemistry could provide a "hidden" reservoir of constituent atoms with the flame structure. However, no stable species were found that exceeded $1 \%$ of the least abundant reported stable species and no radical species were found that exceeded $1 \%$ of the least abundant reported radical species.

While no numerical modeling has yet been done on this system, other characteristics evident in Figures 2 and 6 can be discussed in qualitative terms. Nitrous oxide is known to easily produce $\mathrm{O}$ by collision with a collision partner in flames. Since $O$ is a trace species, it does not take much nitrous oxide decomposition to produce measurable signal. Molecular nitrogen (the other product of the reaction) is also evident at this point early in the flame. It is therefore not surprising that $O$ concentration starts early in the flame. It is, however, surprising that it reaches its maximum early in the flame.

The $\mathrm{OH}$ profile in other flames that we have studied appears to be closely coupled with the temperature profile as well as with the $\mathrm{H}_{2} \mathrm{O}$ profile. This flame also exhibits the same behavior. The temperature profile does not start rapid increase until about 4-5 $\mathrm{mm}$ and peaks about $12 \mathrm{~mm}$, the $\mathrm{OH}$ profile starts about $6 \mathrm{~mm}$ (ignoring the small peak) and peaks about $13-15 \mathrm{~mm}$, and the $\mathrm{H}_{2} \mathrm{O}$ profile starts increasing about 5-6 mm and has achieved the majority of its maximum concentration by $13-15 \mathrm{~mm}$. 


\section{Conclusions}

Molecular beam mass spectrometry with a triple quadrupole mass spectrometer was used to determine concentration profiles (both relative and absolute, when possible) for all major and mosl minor flame species (both stable and radical) in the $\mathrm{C}_{2} \mathrm{H}_{4} / \mathrm{N}_{2} \mathrm{O} /$ Ar flame at 20 torr. Collision-induced dissociation of initial ions at $m / z 28$ and 44 enabled resolution of the primary ion signal into the contributions of the various species present at these nominal masses. The combustion history of the flame was then clearly evident in the consumption of reactants and appearance of products. Minor flame products $\mathrm{CO}, \mathrm{NO}$, and $\mathrm{O}_{2}$ were also noted. Appearance of products was also correlated with temperature profile obtained by thermocouple.

\section{Acknowledgments}

This work was supported in part by the Office of Naval Research (ONR contract no. 00001491MP24001) and by the BRL Combustion mission program. Support from the NRC/BRL Postdoctoral Research Program (SLH) and the PIF/OSD Capital Investment Program (RCS) is gratefully acknowledged.

\section{References}

1. Lucht, R. P.; Salmon, J. T.; King, G. B.; Sweeney, D. W.; Laurendeau, N. M. Optics Lett. 1983, 8, 365.

2. Alden, M.; Edner, H.; Grafstrom, P.; Svanberg, S. Optics Commun. 1982, 42, 244.
3. Goldsmith, J. E. M. I. Chem. Phys. 1983, 78, 1610.

4. Eltenton, G. C. I. Chem. Phys. 1947, 15, 455.

5. Seery, D. J.; Zabielski, M. F. Combust. Flame 1989, 78, 169

6. Biordi, J. C.; Lazzara, C. P.; Papp, J. F. Combust. Flame 1974, 23,73 .

7. Greene, H. A.; Pust, H. Anal. Chem. 1958, 30, 1039.

8. Fristrom, R. M.; Westenberg, A. A. Flame Structure; McGraw-Hill: New York, 1965.

9. Banna, S. M. Ph.D. thesis, University of California, Berkeley, 1979.

10. Knewstubb, P. F, Sugden, T. M. Nature 1958, 181, 1261.

11. Eltenton, G. C. J. Chem. Phys. 1947, 15, 455.

12. Revet, J. M.; Puechberty, D.; Cottereau, M. J. Combust. Flame 1978, 33, 5 .

13. Smith, O. I. Combust. Flame 1981, 40, 187.

14. Smith, O. I.; Chandler, D. W. Combust. Flame 1986, 63, 19.

15. Colket, M. B. III; Chiappetta, L; Guile, R. N.; Zabielski, M. F.; Seery, D. J. Combust. Flame 1982, 44, 3.

16. Howard, S. L.; Locke, R. J.; Sausa, R. C.; Miziolek, A. W. Rapid. Commun. Mass Spcctrom. 1992, 6, 278.

17. Kent, J. H. Combust. Flame 1970, 14, 279.

18. Gaydon, A. G; Wolfhard, H. G. In Third Syntposium on Combustion ard Explosion Phenomena; Williams \& Wilkins: Baltimore, 1949; p. 504.

19. Salmon, J. T.; Laurendeau, N. M. Applied Optics 1987, 26 , 2881.

20. Hayhurst, A. N.; Kittelson, D. B. Combust. Flame 1977, 28, 301.

21. Peterson, R. C. Ph.D. thesis, Purdue University, 1981.

22. Liley, P. E.; Gambill, W. R. In Chemical Engineers Handbook, 5th ed.; Perry, R. H.; Chilton, C. H. Eds.; McGraw-Hill; New York, 1973; Section 3.

23. Warnatz, J. Ber. Bunsenges. Phys. Chem. 1978, 82, 834.

24. Coffee, T. P. Combust. Flame 1986, 65, 53. 